\title{
Predation by an Eastern Brownsnake, Pseudonaja textilis (Duméril, Bibron, \& Duméril 1854), on a Mallee Black-backed Snake, Parasuta nigriceps (Günther 1863)
}

\author{
Gerrut Norval ${ }^{1}$ and Michael G. Gardner ${ }^{1,2}$
}

${ }^{1}$ College of Science and Engineering, Flinders University, Adelaide, South Australia, Australia (norv0003@flinders.edu.au) ${ }^{2}$ Evolutionary Biology Unit, South Australian Museum, North Terrace Adelaide 5000, South Australia, Australia (michael.gardner@flinders.edu.au)

Photographs by the senior author.

$P^{\prime}$ redation can have a dramatic effect on ecosystem dynamics by influencing predator and prey characteristics, populations, and communities (Sih et al. 1985). Consequently, documented predator-prey observations should identify both the predator and prey species to the lowest taxonomic level possible to expand the natural history knowledge of both species involved. Herein we report an instance of an Eastern Brownsnake, Pseudonaja textilis (Duméril, Bibron, \& Duméril 1854), preying on a Mallee Black-backed Snake, Parasuta nigriceps (Günther 1863).

At ca. 1600 h on 14 November 2017, we collected the remains of a $P$. textilis from the side of a dirt road in the Mid North region of South Australia (335' $49^{\prime \prime} S, 139^{\circ} 16^{\prime} 53^{\prime \prime E}$, datum: WGS84; elev. $193 \mathrm{~m}$ ). The tail of the snake was complete and had a length of $133 \mathrm{~mm}$. Based on the snout-vent length (SVL) to tail length (TL) ratio (4.31:1) of another female Eastern Brownsnake roadkill collected a week earlier in the same area, we estimated that the snake had had a SVL of ca. $570 \mathrm{~mm}$. Dissection of the snake revealed that its stomach contained an intact female $P$. nigriceps with a SVL and TL of $307 \mathrm{~mm}$ and $40 \mathrm{~mm}$, respectively. The digestive tract of the $P$. nigriceps in turn contained the partly digested remains of a Dark-spined Blindsnake, Anilios bicolor (Peters 1858) (Fig. 1).

Pseudonaja textilis occurs throughout most of eastern Australia, ranging from lower Cape York Peninsula in Queensland through New South Wales and Victoria to southeastern South Australia (Cogger 2014). It is a habitat generalist and can occur in a wide variety of habitats, including humid habitats, such as coastal heath, to more arid situations, such as inland grasslands and arid scrubs (Coombe 2011; Cogger 2014). Eastern Brownsnakes are predominantly diurnal, although they may also occasionally be active on warm evenings (Coombe 2011; Cogger 2014). Pseudonaja textilis

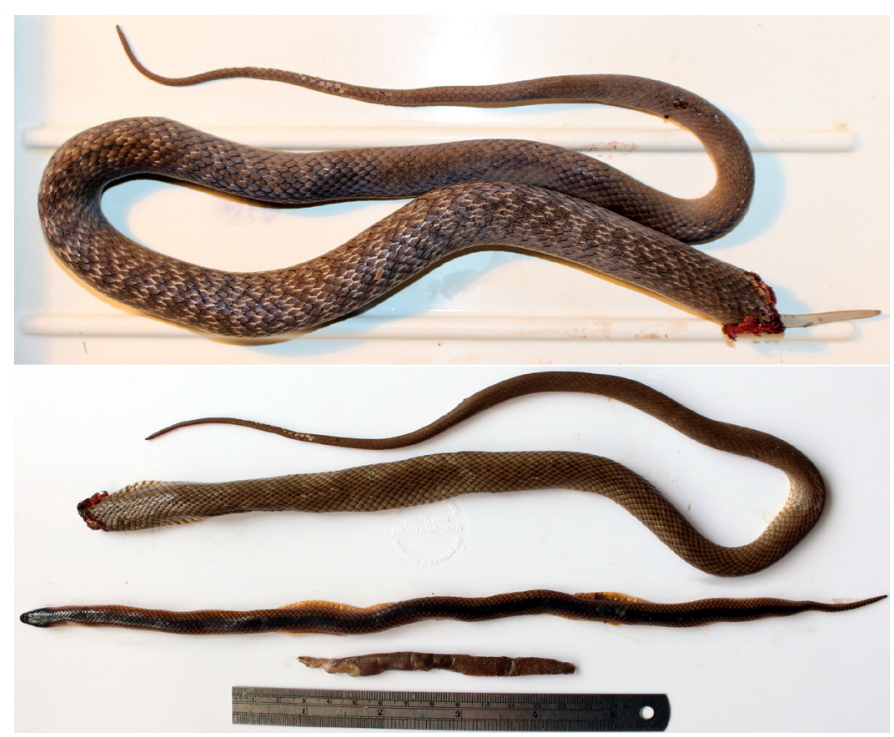

Fig. 1. The remains of a road-killed Eastern Brownsnake (Pseudonaja textilis) prior to dissection (top; note the tail tip of the prey item protruding from the carcass) and (bottom) the three snake species from top to bottom: Pseudonaja textilis, Mallee Black-backed Snake, Parasuta nigriceps; and Dark-spined Blindsnake, Anilios bicolor after dissection.

tends to prey on small mammals and reptiles, although it has been recorded to prey on lizard eggs, some frogs, and small birds (Shine 1977; Coombe 2011; Cogger 2014). Eastern Brownsnakes are active foragers (Coombe 2011) and can visually distinguish prey, such as lizards (Fig. 2), even when the prey remains still (Fleay 1943; Fenner et al. 2008). This explains why the majority of the species recorded as prey of these snakes (Table 1) are diurnal. The presence of prey species such as the rodents, which usually are nocturnal, could involve individuals active by day under some condition, but a more likely explanation is that $P$. textilis actively investigates burrows 


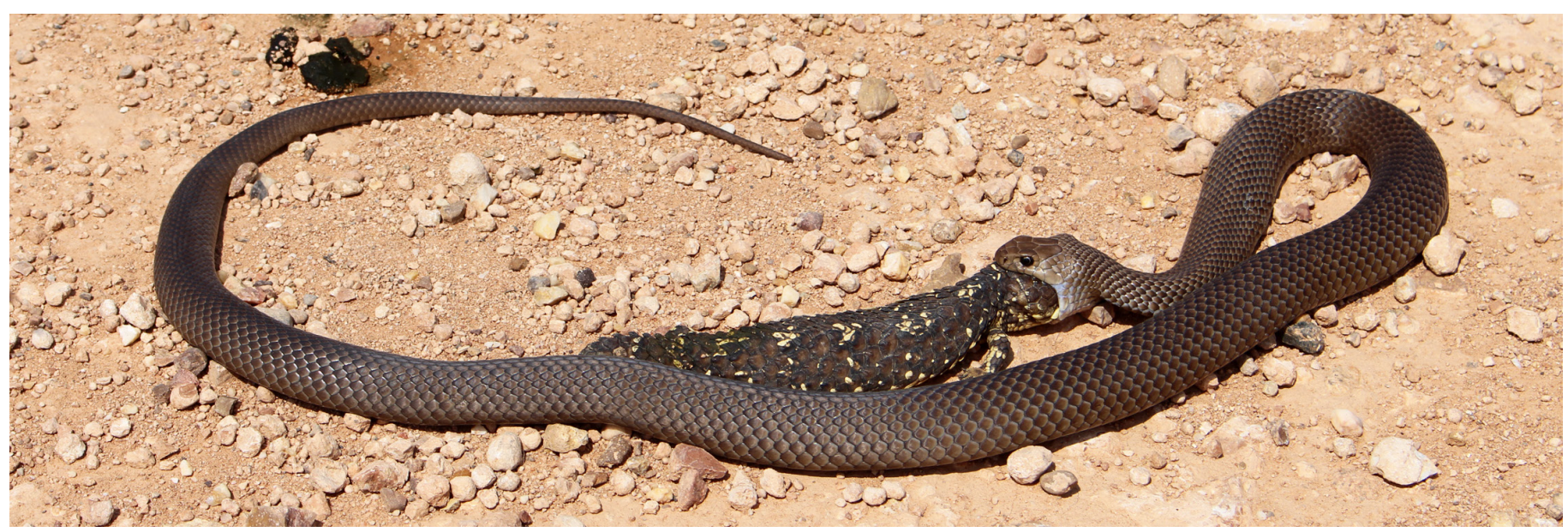

Fig. 2. An Eastern Brownsnake (Pseudonaja textilis) found at $1135 \mathrm{~h}$ on 20 September 2017 preying on a juvenile (SVL $173 \mathrm{~mm}$; TL $40 \mathrm{~mm}$; body mass $94 \mathrm{~g})$ Sleepy Lizard (Tiliqua rugosa) in the Mid North Region of South Australia.

Table 1. A summary of species that have been reported previously as prey of the Eastern Brown Snake, Pseudonaja textilis. An asterisk $\left({ }^{*}\right)$ denotes that a synonym was used in the literature cited. References: ${ }^{1}$ Shine (1989); ${ }^{2}$ Roberts and Mirtschin (1991); ${ }^{3}$ Armstrong and Reid (1992); ${ }^{4}$ Valentic (1996).

\begin{tabular}{|c|c|c|}
\hline Type & Family & Species \\
\hline \multirow[t]{4}{*}{ Frogs } & Hylidae & Litoria caerulea $^{1}$ \\
\hline & & Litoria fallax ${ }^{1}$ \\
\hline & Myobatrachidae & Limnodynastes fletcheri $^{1}$ \\
\hline & & Limnodynastes tasmaniensis \\
\hline \multirow[t]{25}{*}{ Lizards } & Agamidae & Amphibolurus muricatus $^{1}$ \\
\hline & & Ctenophorus nuchalis $^{1}$ \\
\hline & & Pogona barbata ${ }^{1}$ \\
\hline & & Pogona vitticeps ${ }^{1}$ \\
\hline & Gekkonidae & Christinus marmoratus $^{* 1}$ \\
\hline & & Gehyra variegata ${ }^{1}$ \\
\hline & & Lucasium stenodactylum ${ }^{* 1}$ \\
\hline & Scincidae & Carlia tetradactyla \\
\hline & & Ctenotus inornatus $^{* 1}$ \\
\hline & & Cyclodomorphus gerrardit ${ }^{* 1}$ \\
\hline & & Eulamprus quoyii \\
\hline & & Hemiergis decresiensis $^{1}$ \\
\hline & & Hemiergis peronii ${ }^{1}$ \\
\hline & & Lampropholis delicata ${ }^{1}$ \\
\hline & & Lampropholis guichenoti ${ }^{1}$ \\
\hline & & Lampropholis platynotum ${ }^{1}$ \\
\hline & & Lerista bougainvillii ${ }^{1}$ \\
\hline & & Lerista labialis $^{1}$ \\
\hline & & Menetia greyii ${ }^{1}$ \\
\hline & & Morethia adelaidensis ${ }^{1}$ \\
\hline & & Morethia boulengeri ${ }^{1}$ \\
\hline & & Morethia obscura $^{1}$ \\
\hline & & Tiliqua adelaidensis ${ }^{3}$ \\
\hline & & Tiliqua rugosa $a^{2}$ \\
\hline & & Tiliqua scincoides ${ }^{4}$ \\
\hline \multirow[t]{2}{*}{ Snakes } & Elapidae & Denisonia devisi ${ }^{1}$ \\
\hline & & Pseudonaja textilis $^{1}$ \\
\hline \multirow[t]{5}{*}{ Mammals } & Leporidae & Oryctolagus cuniculus ${ }^{1}$ \\
\hline & Muridae & Mus domesticus ${ }^{1}$ \\
\hline & & Rattus lutreolus ${ }^{1}$ \\
\hline & & Rattus rattus ${ }^{1}$ \\
\hline & & Rattus tunneyi ${ }^{1}$ \\
\hline
\end{tabular}

and other shelters for possible prey, which are then located primarily by scent (Fenner et al. 2008; Coombe 2011).

Parasuta nigriceps (Fig. 3) occurs in semi-arid parts of southern Australia from southwestern Western Australia to western Victoria and southwestern New South Wales (Cogger 2014). Mallee Black-backed Snakes prey primarily on agamids, geckos, skinks, and their eggs, although they may opportunistically consume blindsnakes, as described herein, and small elapids (Coombe 2011). Since these snakes are nocturnal, they tend to shelter in leaf litter or under objects such as rocks and fallen branches during the day (Coombe 2011; Cogger 2014). Although P. nigriceps and P. textilis might both be active at dawn or dusk, the time of day of our observation and the undigested state of the prey item, suggest that the $P$. textilis most likely consumed the $P$. nigriceps while it was sheltering. To the best of our knowledge, this is the first reported instance of $P$. textilis predation on $P$. nigriceps.

\section{Acknowledgements}

We express our gratitude to Simon Adamczyk, Bonnie Derne, and Aaron Fenner for their input concerning the diet and behavior of $P$. textilis. The observations presented herein were

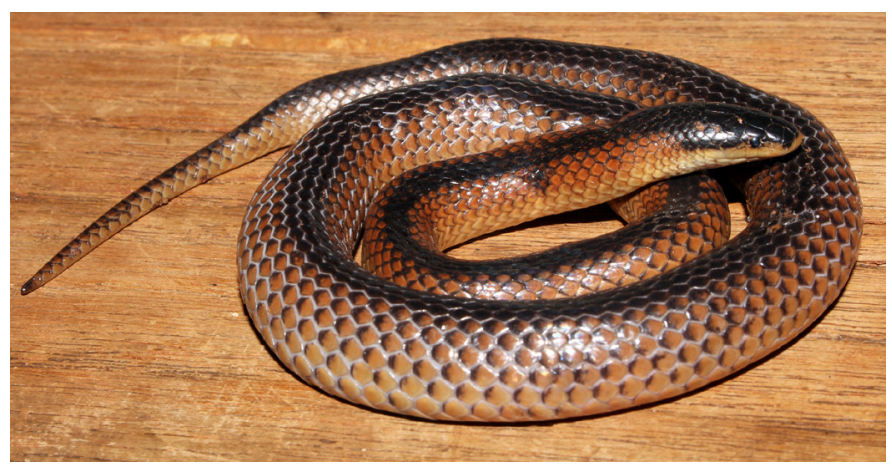

Fig. 3. The Mallee Black-backed Snake (Parasuta nigriceps) described herein after it had been removed from the disgestive tract of the Pseudonaja textilis. Note the lack of signs of the onset of digestion. 
made by the senior author while conducting surveys as part of his doctoral research, which was partly funded in 2017 by a grant from the Royal Society of South Australia to Gerrut Norval. Clearance for the research was granted by the Animal Welfare Committee of Flinders University (No.: E454/17) and the Department of Environment, Water and Natural Resources of the Government of South Australia (Permit No.: A23436-25).

\section{Literature Cited}

Armstrong, G. and J. Reid. 1992. The re-discovery of the Adelaide Pygmy Bluetongue, Tiliqua adelaidensis (Peters, 1863). Herpetofauna 22: 3-6.

Cogger, H.G. 2014. Reptiles and Amphibians of Australia. 7th ed. CSIRO Publishing, Collingwood, Victoria, Australia.

Coombe, G. 2011. Snakes of South Australia. Wildlife on the Web, Australia.
Fenner, A.L., J.A. Schofield, A.L. Smith, and C.M. Bull. 2008. Observations of snake predation on the Pygmy Bluetongue Lizard, Tiliqua adelaidensis. Herpetofauna 38: 105-109.

Fleay, D. 1943. The Brown Snake-dangerous fellow. The Victorian Naturalist 59: $147-152$

Roberts, J. and P. Mirtschin. 1991. An uncommon prey record for the Brown Snake Pseudonaja textilis. Herpetofauna 21: 36.

Shine, R. 1977. Habitats, diets, and sympatry in snakes: A study from Australia. Canadian Journal of Zoology 55: 1118-1128.

Shine, R. 1989. Constraints, allometry, and adaptation: Food habits and reproductive biology of Australian Brownsnakes (Pseudonaja: Elapidae). Herpetologica 45: 195-207.

Sih, A., P. Crowley, M. McPeek, J. Petranka, and K. Strohmeier. 1985. Predation, competition, and prey communities: A review of field experiments. Annual Review of Ecology and Systematics 16: 269-311.

Valentic, R. 1996. A prey record of the Eastern Blue-tongue Tiliqua scincoides for the Common Brown Snake Pseudonaja textilis. Monitor 8: 84. 